\title{
De práticas a capacidades: a atuação de procuradores do Ministério Público Federal no caso de Belo Monte ${ }^{1}$
}

\author{
Luiz Vilaça \\ Doutorando de Sociologia (University of Notre Dame). \\ South Bend, United States \\ Ivilaca@nd.edu
}

Resumo

Esta pesquisa analisa etnograficamente os processos de construção e transformação de capacidades estatais no Ministério Público Federal (MPF) no contexto de implementação da usina de Belo Monte. Desde 2001, procuradores vêm mobilizando uma série de ações - judiciais e extrajudiciais - que contestam o modo como a barragem está sendo implementada e buscam mitigar seus impactos socioambientais. Neste artigo, exploro como três tipos de práticas de procuradores - os recrutamentos de aliados, as articulações internas e as bricolagens - mudaram as maneiras pelas quais o órgão vem atuando em processos de implementação de grandes projetos. Argumento que essas práticas geraram aprendizagens organizacionais que se traduziram na construção e transformação de diferentes tipos de capacidades no MPF, ressaltando assim o caráter dinâmico das capacidades estatais e a importância de olhar para o que estão efetivamente fazendo os agentes estatais que dão vida a essas capacidades.

Palavras-chave: Ministério Público, Belo Monte, capacidades estatais, práticas.

A usina hidrelétrica de Belo Monte (BM) - que hoje está em operação no rio Xingu, próximo à cidade de Altamira, no Pará - é um empreendimento já há muito tempo pensado por agências estatais no Brasil. Os primeiros estudos sobre a usina datam da década de 1970, ainda

1 Este trabalho foi desenvolvido com base na minha pesquisa de mestrado em Ciência Política na Universidade de Brasília. Agradeço pelos comentários em versões anteriores deste trabalho de Rebecca Abers, Marisa von Bülow e Carla Teixeira, bem como dos(as) pareceristas da revista. 
no período ditatorial. Desde o princípio, a ideia de construir BM - que na época se chamava Kararaô - gerou muitas polêmicas. Por ser um empreendimento de grande porte e localizado em ambientes ocupados por populações indígenas e comunidades tradicionais, houve, na década de 1980, grande mobilização contra a construção da usina. Lideranças de comunidades indígenas e membros de Organizações de Movimentos Sociais (OMSs) se articularam para resistir às iniciativas estatais de construir BM, que, por sua magnitude ${ }^{2}$, assustava as comunidades locais.

A grande pressão dos movimentos locais - e também internacionais - fez com o que o Banco Mundial, então financiador do projeto, recuasse, o que se traduziu em um engavetamento do processo de BM (Carvalho, 2006 apud Pereira, 2014, p. 121). Alguns anos mais tarde, a barragem é retomada quando a Eletronorte apresenta uma revisão sobre a versão preliminar do projeto, procurando diminuir a área alagada pela usina (Hochstetler, 2011). Todavia, foi a partir da virada do século que Belo Monte realmente assumiu status de prioridade na agenda, sendo destacada pelo governo como projeto de "interesse estratégico" para o país (Pereira, 2014).

A partir daí, Belo Monte é aprovada no Congresso Nacional em 2005, dando início ao processo de licenciamento ambiental do empreendimento. Nesse momento, entram em cena vários outros órgãos estatais, como o Ministério Público Federal (MPF) ${ }^{3}$, e agências licenciadoras, como Instituto Brasileiro do Meio Ambiente e dos Recursos Naturais Renováveis (IBAMA) e a Fundação Nacional do Índio (FUNAI). O MPF tem sido especialmente ativo. Procuradores ajuizaram, por exemplo, 27 ações judiciais relacionadas à usina entre os anos de 2001 e 2016. Além da atuação judicial, procuradores também acionaram órgãos licenciadores, convocaram outras instituições para participar no processo e promoveram uma inspeção em comunidades afetadas pelo empreendimento.

A presença intensa de procuradores durante o processo de implementação de Belo Monte - por vezes questionando a legitimidade da barragem e defendendo comunidades impactadas - produziu e ainda produz diversos efeitos na política, como paralisações na construção/operação do empreendimento e mudanças nas políticas de compensação

2 Belo Monte foi apresentada como uma das três maiores hidrelétricas do mundo em termos de potência instalada, com 11.233 Megawatts (MW) (Fonte: NORTE ENER GIA. Usina hidrelétrica Belo Monte. Disponível em: <http://norteenergiasa.com.br/site/portugues/usina-belo-monte>. Acesso em: 28 mar. 2017). Não há consenso, no entanto, em torno da capacidade efetiva da usina, uma vez que, devido à redução do reservatório em alguns períodos do ano, a capacidade instalada seria "alcançada apenas por três meses no ano" (Pereira, 2014, p. 126). De acordo com Bermann (2012), a capacidade média da usina deve girar em torno de 4.428 MW por ano.

3 O caso de Belo Monte esteve concentrado no MPF por prevalecer um entendimento no Ministério Público de que se trata de uma obra de atribuição federal e não estadual. Para procuradores entrevistados, a atribuição federal do empreendimento estava evidenciada na presença da obra em planejamentos governamentais do âmbito federal e no investimento de recursos via Banco Nacional do Desenvolvimento (BNDES): "como há muita verba federal na obra, e é uma obra do PAC [Programa de Aceleração do Crescimento], é uma questão energética, que é um tema relacionado também à esfera federal, a dinheiro do BNDES, tudo isso acaba trazendo a atribuição para a justiça federal” (Entrevista 12, MPF, 2015). 
da Norte Energia, empresa responsável pelo empreendimento ${ }^{4}$. Mas talvez até mais importante, essa mobilização de procuradores vem transformando as maneiras pelas quais o MPF atua em processos de implementação de grandes obras. Uma das principais armas de procuradores - as ações judiciais -, por exemplo, tem dado lugar cada vez mais a costuras de relações com outros atores envolvidos no processo da usina.

Mas o que explica essas mudanças dentro do MPF? De que maneiras organizações estatais transformam o modo como atuam ou constroem novos modos de atuação no processo de formulação e implementação de políticas públicas? Em outras palavras, como capacidades estatais são construídas e transformadas? Esses questionamentos me fizeram buscar as práticas dos procuradores do MPF e os efeitos que elas produziram dentro da instituição. Nesse sentido, argumento que as práticas acionadas por atores estatais podem gerar aprendizagens organizacionais que se traduzem na construção e transformação de capacidades das organizações nas quais eles trabalham. Exploro, neste artigo, como três tipos de práticas acionadas por procuradores no contexto de Belo Monte - recrutamentos de aliados, articulações internas e bricolagens - mudaram como a organização lida com a instalação de grandes projetos, construindo capacidades participativas e de coordenação intra e interburocrática.

Este trabalho foi construído a partir de uma perspectiva etnográfica $a^{5}$ baseada em três fontes de informação. Em primeiro lugar, foi feita uma análise documental sobre ações civis públicas, inquéritos civis, decisões judiciais, notas técnicas, pareces, entre outros documentos. Além disso, foram realizadas 79 entrevistas semiestruturadas com atores-chave, tais como procuradores da República, membros de OMSs, indivíduos e grupos afetados pelo empreendimento, e servidores de agências estatais envolvidas no processo, como o IBAMA e a FUNAI ${ }^{6}$. Por fim, também lancei mão de observações em reuniões, encontros e eventos durante os meses de agosto e setembro de 2016 na cidade de Altamira, tendo acompanhado, durante o período de uma semana, o trabalho de uma das procuradoras da Procuradoria da República do Município de Altamira (PRM-Altamira).

4 O licenciamento ambiental e um processo administrativo que regula o uso de recursos ambientais, sendo orientado para a prevenção de danos ao meio ambiente (Sánchez, 2013). Para atestar a viabilidade do projeto, o empreendedor deve obter três licenças junto ao IBAMA: a Licença Prévia, a Licença de Instalação e a Licença de Operação (Pereira, 2014).

5 Entendo por etnografia - inspirado por Oliveira (2009), Peirano (2014), e Castilho, Souza Lima e Teixeira (2014) - um modo de produção de conhecimento que se distingue ao conferir centralidade para os conhecimentos locais, colocando em xeque constante as premissas teóricas que orientam a pesquisa.

6 As entrevistas foram realizadas em cinco momentos diferentes. O primeiro deles foi em uma viagem a Belém e Altamira, em 2012, quando foram entrevistados 7 atores. O segundo momento foi em Brasília, em 2014, quando conversei com mais 3 atores. O terceiro, também em Brasília, compreendeu a entrevista de 5 pessoas, em 2015. As entrevistas ganharam um novo fôlego em 2016, quando pude realizar uma ida a campo (em Belém e Altamira), conseguindo obter mais 61 entrevistas. Em 2017, entrevistei mais 3 procuradores em Brasília. 
A contribuição central desta pesquisa reside na iluminação dos processos por meio dos quais agentes estatais, ao buscarem resolver problemas cotidianos, materializam, constroem e transformam capacidades desse "Estado" (Migdal, 2004, p. 112). Nesse sentido, mostro neste artigo de que maneiras as práticas de atores estatais podem gerar aprendizagens organizacionais que se traduzem na construção e/ou transformação de capacidades. Entendo que o deslocamento analítico proposto por essa pesquisa - do olhar macro sobre como instituições são dotadas ou não de certas capacidades para uma perspectiva micro atenta para as práticas acionadas por agentes estatais no seu dia a dia - ressalta os potenciais de contribuição de análises qualitativas para o debate em torno de capacidades estatais.

Este artigo está dividido em quatro seções, além desta introdução. Na próxima seção, situo a pesquisa nos debates sobre capacidades estatais, ressaltando a importância de estudos sobre organizações e o papel dos atores para a compreensão do caráter dinâmico das capacidades. Na seção seguinte, apresento brevemente a trajetória do Ministério Público no sistema político brasileiro. Na terceira parte do artigo, ilumino três tipos de práticas acionadas por procuradores durante o caso de Belo Monte: o recrutamento de aliados, as articulações internas e as bricolagens. Logo após, explico como essas práticas geraram aprendizagens organizacionais que se traduziram na construção e transformação de capacidades estatais no Ministério Público Federal. Por fim, apresento algumas considerações finais resumindo o argumento do trabalho.

\section{Práticas e aprendizagens: a dinamicidade das capacidades estatais}

Os estudos sobre capacidades estatais passaram a ganha fôlego nas ciências sociais com a "virada" estatista nas décadas de 1970 e 1980 (Cingolani, 2013), especialmente a partir da obra clássica de Evans, Rueschemeyer e Skocpol (1985), Bringing the State Back In. Nesse momento, a preocupação central era identificar que tipos de capacidades estatais estão presentes e ausentes em diferentes instituições do Estado e compreender que fatores levam alguns Estados a conseguir implementar políticas e outros não.

Desde então, a literatura sobre capacidades estatais tomou rumos diversos, principalmente pela variedade e heterogeneidade de estudos desenvolvidos nessa perspectiva. Algumas questões analíticas, contudo, ganharam maior atenção de pesquisadores. De fato, o foco de grande parte dos autores que se debruçam nesse debate têm sido de investigar que tipos de capacidades estão presentes e ausentes em determinadas instituições do Estado e explicar como essa variação produz (ou não) diferentes transformações sociais (Painter; Pierre, 2005; Besley; Persson, 2010). Foi dada ainda uma forte atenção à mensuração das capacidades estatais, como no trabalho de pesquisadores que construíram índices de capacidades, geralmente direcionados para a diferenciação do que seriam Estados "fortes" e "fracos" (Rice; Patrick, 2008; Cárdenas, 2009; Ottervik, 2013; Luna; Maureira, 2014).

Pouca atenção foi dada, contudo, para como essas capacidades são materializadas de diferentes maneiras nas ações concretas de agentes estatais, e menos ainda para como es- 
sas capacidades são construídas e transformadas dentro de organizações estatais. Entendo que uma das principais razões para isso esteja localizada no recorte metodológico dessas pesquisas, em sua maioria desenhadas a partir de estudos quantitativos ancorados em um grande número de casos (Luna; Maureira, 2014).

Apesar de revelarem importantes padrões e tendências, o enfoque em explicações estruturais, que pouco se dedica a olhar para agência dos atores estatais, parece levar a um descolamento das capacidades em relação aos atores que dão vida a elas. Em outras palavras, é como se capacidades existissem independentemente de quem está à frente das instituições estatais acionando, atualizando e transformando essas capacidades na formulação e implementação de políticas públicas. Talvez até mais importante, isso significa que o grande esforço para entender os efeitos das práticas de burocratas na implementação de políticas públicas - sobre como por exemplo eles conseguem ou não implementar políticas em determinados contextos - não foi acompanhado de uma preocupação em sistematizar os efeitos que essas práticas produzem dentro das próprias organizações estatais.

As literaturas sobre administração e gestão de organizações podem ajudar aqui. Existe, afinal, uma longa tradição nos estudos sobre organizações do setor privado que buscam ressaltar justamente a dinamicidade dessas organizações - isto é, como elas aprendem e se transformam ao buscarem resolver problemas (Levitt; March, 1988; Schulz, 2001; Senge, [1990] 2004). Nesse sentido, muito tem se debatido sobre os processos e mecanismos de aprendizagem organizacional, ou seja, sobre como os atores dentro das organizações estão constantemente reavaliando suas práticas e transformando o modo como lidam com problemas futuros.

Para Stata (1989), a aprendizagem organizacional ocorreatravés do compartilhamento de insights e conhecimentos, e se desenvolve a partir de experiências passadas. Nesse sentido, organizações, ao invés de serem tomadas como algo "dado", passam a ser compreendidas enquanto feixes de relações em movimento que estão constantemente se (re) produzindo, atualizando e transformando (Berk; Galvan, 2013) ${ }^{7}$. Como lembram Nonaka, Toyama e Byosière (2001, p. 492, tradução nossa ${ }^{8}$ ),

"Quando organizações inovam, elas não estão simplesmente processando informações. [...] Ao invés de simplesmente resolverem problemas, organizações criam e definem problemas, desenvolvem e aplicam novos conhecimentos para resolver esses problemas, e ainda desenvolvem novos conhecimentos através de atividades voltadas para a resolução de problemas. Uma organização não é simplesmente uma máquina de processor informação, mas uma entidade que cria conhecimento através de ações e interações”.

Berk; Galvan; Hattam (2013, p. 42, tradução nossa) ressaltam que "muitos atores [...] aprendem com os esforços criativos de outros atores. Eles observam, comparam, se inspiram e avaliam. Isso não é uma cópia, mas uma verdadeira aprendizagem social, uma vez que cada contexto exige novas ações e que atores mobilizem recursos de maneiras diferentes. A cada vez que atores criativos aprendem, eles reavaliam suas próprias ações à luz de suas observações das ações criativas de outros atores". Texto original em inglês.

8 Texto original em inglês. 
Apesar de não haver consenso em torno do conceito de aprendizagem organizacional (Ortenblad, 2001), diversos autores vêm buscando enfatizar os efeitos que práticas de experimentação - em que atores mobilizam recursos de maneiras novas para resolver problemas (Abers; Keck, 2013) - produzem nas capacidades dessas organizações atingirem seus objetivos de maneira mais eficiente (March, 1991; Perin et al., 2006).

Essa atenção especial às práticas dos atores, por sua vez, pode ser remontada às teorias pragmatistas, que já há algum tempo vêm buscando destrinchar os sentidos e efeitos das práticas dos atores. Um dos principais expoentes dessa corrente de pensamento, John Dewey (1980, p. 140, tradução nossa ${ }^{9}$ ), argumenta que:

“aprender por experiência é uma conexão que vai e volta entre o que fazemos com as coisas e o que aproveitamos ou sofremos dessas coisas em consequência. Nessas condições, fazer se torna tentar; um experimento com o mundo para descobrir como ele é. [...] A medida do valor de uma experiência está ligada à percepção de relações ou continuidades que ela produz".

Nesse sentido, o olhar micro para os atores que habitam organizações estatais (Hallett; Ventresca, 2006) se torna fundamental para a compreensão de como as capacidades das organizações nas quais eles estão inseridos são (re)produzidas e transformadas. Afinal, como bem lembra Mazzuca (2012, p. 557, tradução nossa ${ }^{10}$ ), “o lócus das chamadas capacidades estatais na realidade é a administração como corpo de funcionários”.

Se capacidades se referem ao corpo de servidores do Estado, entender como essas capacidades são construídas requer um olhar mais atento para o que estão efetivamente fazendo os agentes que dão vida a esse Estado. De fato, se voltamos ao próprio Weber (2004) - um dos pioneiros das análises sobre o funcionamento dos Estados modernos -, vemos como a burocracia, apesar de ser vista através de documentos e regras, é feita de pessoas. Os burocratas, para Weber, não são simplesmente seres insulados que aplicam regras de maneira racional e impessoal, mas atores culturalmente situados, e que podem até agir criativamente (Herzfeld, 1993). Assim, a operação da burocracia depende de como os atores que trabalham ali interpretam suas ações (Schluchter, [1979] 1985, p. 112) ${ }^{11}$. Afinal, como lembram Castilho, Souza Lima e Teixeira (2014, p. 14),

“os burocratas no cotidiano das agências da administração pública [...] permanentemente procedem a (re)arranjos, (re)configurações, (re)interpretações do que sejam os modos de atender às demandas das coletividades sobre as quais atuam, assim estabelecendo fronteiras (e a crença nelas) do que seja "o Estado", conferindo-lhe, portanto, a materialidade que as ideias podem ter.

9 Texto original em inglês.

10 Texto original em espanhol.

11 A interpretação de Weber aqui, assim, é diferente do que propunham algumas abordagens do Estado que seguem uma linha neoinstitucionalista (como, por exemplo, Evans, Rueschemeyer e Skocpol 1985), cuja retomada da teoria weberiana veio no sentido de reforçar o caráter técnico e insulado de atuação dos burocratas. 
A proposta deste artigo - seguindo a "virada cultural" nos estudos estatais proposta por Steinmetz (1999) - é de tentar “pegar o Estado por dentro”, isto é, de ver onde estão os sujeitos que dão vida às capacidades estatais: quem são, o que pensam e que mecanismos acionam no seu trabalho cotidiano - e por isso vamos às práticas ${ }^{12}$.

\section{De advogado do Estado a "guardião da sociedade": o papel do Ministério Público na política brasileira}

O Ministério Público é atualmente caracterizado por defender interesses difusos e coletivos, além de exercer controle sobre a atuação de outras organizações, estatais e sociais. Sua atribuição hoje, assim, envolve não somente a tradicional função de persecução criminal, mas um amplo papel na esfera cível (Arantes, 2007). Esse formato de MP tal como conhecemos hoje, contudo, é fruto de uma série de processos históricos e políticos que ocorreram durante as últimas décadas, principalmente no decorrer do processo de redemocratização do Brasil nos anos 1980.

Apesar de não ser possível reconstruir esse processo aqui ${ }^{13}$, acredito ser importante resgatar algumas particularidades que fizeram com o que o MP se tornasse um órgão muito distinto da maioria das agências estatais. De uma organização dedicada à procuração criminal, controlada pelo poder executivo (McAllister, 2008) e muitas vezes subordinada por interesses políticos (Coslovsky, 2009), o Ministério Público tornou-se autônomo em relação aos outros poderes, passando a desempenhar uma função de defensor dos interesses da sociedade e de "cão de guarda" do Estado (Arantes, 2007).

Importantes leis como a Política Nacional do Meio Ambiente ${ }^{14}$ - que formalizou a existência do meio ambiente enquanto um interesse difuso ${ }^{15}$ e atribuiu competência ao MP para defendê-lo (Arantes, 2002) - e a Lei da Ação Civil Pública (ACP), ${ }^{16}$ que regula-

12 É importante deixar claro, desde já, que apesar da literatura de capacidades estatais ter como foco a implementação de políticas por agências do Executivo, neste trabalho o desafio é compreender a construção de capacidades em uma agência de controle - que é inclusive independente do poder Executivo (Arantes, 2002) -, o Ministério Público Federal.

13 Para uma análise mais profunda e detalhada sobre esses processo de transformação do MP, ver a contribuição preciosa de Arantes (2002).

14 Lei número 6.938 de 1981.

15 Interesses difusos "são os transindividuais de natureza indivisível de que sejam titulares pessoas indeterminadas e ligadas por circunstâncias de fato" (Arantes, 1999, p. 88). Eles revestem um conjunto amplo e heterogêneo de situações, incluindo, por exemplo, interesses de grupos fracos demais para lutarem por si próprios, interesses de grupos dispersos demais, interesses difundidos mas que não estão concentrados suficientemente em algum grupo em particular, e interesses imateriais que não estão corporificados em grupos específicos.

16 Lei número 7.347 de 1985. 
mentou o uso da $\mathrm{ACP}^{17}$ em casos de danos causados ao meio ambiente, ao consumidor e a patrimônios históricos, culturais ou de valor artístico e estético (McAllister, 2008, p. 24; Hochstetler; Keck, 2007), foram fundamentais na construção dessa nova identidade do órgão.

Mas talvez até mais importante foi a Constituição Federal de 1988, que além de expandir o escopo de atuação do MP (Arantes, 2002), fortaleceu sua autonomia em relação ao poder Executivo (Sadek, 2010; Arantes, 2007). Assim, o órgão passou a desempenhar um papel de "defensor social", mais próximo da sociedade civil do que do aparelho do Estado (Coslovsky, 2009, p. 100) ${ }^{18}$. Contudo, a independência institucional em relação aos outros poderes do Estado não foi a única conquista para o MP através da Assembleia Constituinte; um dos importantes passos dados pela nova Constituição foi ainda de garantir a independência interna dos procuradores e promotores dentro do MP a partir dos princípios que norteiam sua atuação, tais como a independência funcional, a vitaliciedade, a inamovibilidade e irredutibilidade de subsídios ${ }^{19}$, "o que lhes confere alto grau de independência funcional e controle completo sobre as ações que conduzem" (Arantes, 2007, p. 329).

O Ministério Público, assim, passou a ocupar um lugar central no sistema político brasileiro, tornando-se um "agente político da lei”, com "a independência típica dos órgãos judiciais inertes e neutros, porém destinado à ação política de defesa de interesses da sociedade, num quadro em que a lei, como o céu, é o limite" (Arantes, 2002, p. 80, grifo do autor). Desde essa transformação institucional - na qual o MP se tornou autônomo e encarregado de defender interesses de grupos sociais diversos -, procuradores e promotores vêm atuando intensamente em uma variedade de conflitos políticos, como a defesa de grupos minoritários (Vilaça, 2017), do meio ambiente (McAllister, 2008; Losekann, 2013) e o combate à corrupção (Lemgruber et al., 2016).

17 Kerche (2007, p. 274-275) esclarece que "a ação civil pública é um instrumento jurídico que permite a representação, junto ao Poder Judiciário, de interesses coletivos, difusos e individuais homogêneos".

18 Vale ressaltar que a Constituição de 1988, além de consolidar o papel do Ministério Público como defensor da cidadania e dos interesses coletivos, ampliou sua função de agente de controle interestatal, conferindo-lhe poder para atuar como "cão de guarda" do Estado brasileiro (McAllister, 2008). Essa segunda dimensão de responsabilidades do MP é tratada pela literatura que enfatiza seu papel como agente de controle do Estado (Abrucio; Loureiro, 2005; Abrucio, 2011).

19 De acordo com o princípio da independência funcional, promotores e procuradores podem atuar conforme suas próprias opiniões legais, sem depender de diretrizes de cima. A vitaliciedade basicamente quer dizer que, após um período probatório de dois anos, procuradores só podem ser demitidos através de ordens judiciais. Já a inamovibilidade garante que os procuradores não possam ser transferidos e/ou promovidos contra sua vontade. Por fim, a irredutibilidade de subsídios significa que os salários são fixos e não podem ser diminuídos (Coslovsky, 2009). 


\section{Interagindo, articulando e inovando: a atuação de procuradores do MPF no caso de Belo Monte}

No contexto de Belo Monte, a participação do MP - através do Ministério Público Federal - teve início formalmente em 2001, quando o órgão foi procurado por membros do povo indígena Juruna de Paquiçamba, que temiam a construção do empreendimento (Entrevista 1, MPF, 2012). Desde então, mais de 20 diferentes procuradores se envolveram com o caso de Belo Monte - tanto da própria Procuradoria da República do Município de Altamira (PRM-Altamira), como de outras sedes do MPF, tais como Belém e Brasília -, mobilizando uma série de diferentes iniciativas na tentativa de influenciar a disputa política da usina.

Até final do ano de 2016, procuradores do MPF já haviam ajuizado 27 ações judiciais relacionadas ao caso de Belo Monte sobre temas diversos, na maior parte dos casos vinculados a luta por direitos de comunidades afetadas pelo empreendimento, tais como os povos indígenas e ribeirinhos da região (Vilaça, 2017). Ao buscarem defender essas causas - além de tentar garantir a preservação do meio ambiente e questionar problemas nos estudos da usina - procuradores também lançaram mão de outras estratégias, coordenando audiências públicas e inspeções, e negociando extrajudicialmente. Mas o que efetivamente fazem procuradores no cotidiano do MPF? Que práticas eles acionam ao buscar influenciar o rumo de políticas públicas?

Diversas das Ações Civis Públicas ajuizadas por procuradores, por exemplo, contavam com o auxílio de atores externos, em especial lideranças de organizações de movimentos sociais locais e pesquisadores. Como explica um dos procuradores, "as ações, elas basicamente, elas chegam até nós através de representações da sociedade civil" (Entrevista 1, MPF, 2012). Esses atores eram mobilizados justamente porque podiam prover aos procuradores informações e/ou análises valiosas que poderiam dar uma base mais sólida as suas ações (Entrevista 67, MPF, 2016). Nesse sentido, o recrutamento de aliados emerge como uma das práticas acionadas por procuradores no caso de Belo Monte. Como explica um dos coordenadores do Instituto Socioambiental (ISA),

“o MPF tem uma atenção grande para populações que são invisibilizadas. E algumas organizações do movimento social também estão dando força para organizações e populações que são invisibilizadas. [...] Para garantir o direito dessas populações, ele [MPF] precisa buscar informações que não estão na mão do Estado" (Entrevista 76, ISA, 2016).

De fato, das sete reuniões em que participei enquanto observador durante o período em que acompanhei o trabalho de uma das procuradoras, cinco contaram com a presença de lideranças locais, todas membros de organizações de movimentos sociais. Uma das procuradoras destaca que os movimentos da região "servem como informantes, no sentido de apresentar os anseios da população, e ao mesmo tempo, de forma reversa, cobrarem nossa atuação” (Entrevista 12, MPF, 2015). As conversas com esses atores estiveram 
presentes em diversas formas - por meio de reuniões, telefonemas, e-mails e participação em atividades (Entrevista 12, MPF, 2015) ${ }^{20}$.

Além de lideranças de movimentos sociais, pesquisadores da comunidade acadêmica também foram recrutados para auxiliar nas ações construídas por procuradores. A ajuda de pesquisadores foi importante, por exemplo, na coordenação de uma inspeção interinstitucional em comunidades ribeirinhas que habitam as proximidades do rio Xingu. Com a chegada da usina, diversos ribeirinhos - que constituem um dos grupos mais invisíveis nos processos de implementação de hidrelétricas (Entrevista 67, MPF, 2016) - passaram a ser removidos de seus locais de origem. A recusa da Norte Energia de reconhecer a dupla moradia que caracteriza esses grupos - uma vez que eles precisam de uma casa na beira do rio para pescar e outra na cidade para vender os peixes - fez com que muitos deles procurassem o MPF, já que estavam insatisfeitos com as compensações que lhes eram oferecidas (Entrevista 54, Movimento Xingu Vivo para Sempre, 2016).

A procuradora responsável pela questão decidiu então organizar uma visita aos locais de habitação de comunidades ribeirinhas atingidas pelo empreendimento, com o objetivo de visibilizar os impactos sociais da remoção desses grupos de seus locais de origem. Assim, entre os dias 01 e 03 de junho de 2015, foi realizada uma série de inspeções que "destinaram-se a verificar in locu a compatibilidade deste processo de remoção com as normas que o deveriam nortear" (MPF, 2015, p. 4), com o objetivo de "buscar espaços adequados de fala, dando voz a um número representativo de ribeirinhos” (MPF, 2015, p. 17) ${ }^{21}$. A realização dessa inspeção só foi possível, todavia, com a ajuda de membros da comunidade acadêmica. Uma pesquisadora da Universidade de Campinas (UNICAMP) explica que

"por conta desse trabalho que a gente fazia [de pesquisa com os pescadores], a [procuradora] ${ }^{22}$ chamou a gente em maio de 2015 para ajudar a organizar a inspeção do MP. Como a gente trabalhava com os pescadores, ela pediu ajuda para organizar a inspeção. E começamos a fazer um monte de reunião. Todos os ribeirinhos que vinham ao MP, a gente fazia reunião para mapear quais lugares seriam interessantes visitar na inspeção, e a gente organizou

20 É importante ressaltar que essa posição foi corroborada por membros de movimentos sociais da região de Altamira. De fato, das 24 organizações de movimentos sociais entrevistadas, 19 afirmaram já terem acionado e/ou sido acionadas por procuradores do MPF para apresentar denúncias ou demandas: a Federação de Órgãos para Assistência Social e Educacional (FASE), o Movimento Xingu Vivo Para Sempre (MXVPS), o Comitê Metropolitano Xingu Vivo Para Sempre (CMXVPS), o Instituto Socioambiental (ISA), o Conselho Indigenista Missionário (CIMI), o Fórum da Amazônia Oriental (FAOR), o Instituto Amazônia Solidária e Sustentável (IAMAS), a Fundação Viver, Produzir e Preservar (FVPP), o Movimento dos Atingidos por Barragens (MAB), a Comissão Pastoral da Terra (CPT), a Prelazia do Xingu, a Colônia de Pescadores Z-57, o Coletivo de Mulheres de Altamira, o Movimento Negro de Altamira, a Associação Tyroporemo, a Associação Inkuri, a Associação dos Índios Moradores de Altamira (AIMA), a Cooperativa Mista dos Garimpeiros da Ressaca, Itata, Galo, Ouro Verde, e Ilha da Fazenda (COOMGRIF), e a Associação dos Moradores do Bairro Jardim Independente I (AMBAJI I).

22 Os nomes das pessoas mencionadas nas entrevistas foram suprimidos para preservar seu anonimato. 
junto com eles, os roteiros, fez várias visitas antes para mapear um pouco as famílias" (Entrevista 75, UNICAMP, 2016).

O recrutamento de aliados, portanto, foi importante por dois motivos: o acesso que procuradores passavam a ter a informações especializadas e a pressão que esses atores (especialmente militantes) faziam ao MPF cobrando resultados. Como resume uma das procuradoras: "nós [MPF] somos uma instituição, nós temos as nossas limitações, de número mesmo de gente para agir. Então certamente, se você tem uma militância que tá o tempo todo the cobrando, você vai agir mais, e, talvez, melhor" (Entrevista 15, MPF, 2016).

Além de recrutar aliados, procuradores também se articularam internamente dentro do próprio Ministério Público. Por estar localizada em uma cidade com custo de vida relativamente alto - principalmente após a chegada da barragem - e carente em serviços de infraestrutura, a Procuradoria da República do Município de Altamira tinha dificuldades em atrair e manter procuradores (Entrevista 12, MPF, 2015). Isso significa que a grande maioria dos procuradores que chegava, estava no que eles chamam de sua "primeira lotação" - isto é, o primeiro posto de trabalho que ocupam após a admissão no concurso do MP (Entrevista 21, MPF, 2016). Além disso, a PRM-Altamira sofria de uma alta rotatividade, com os procuradores geralmente ficando em média dois a três anos na cidade. Somando-se a isso o intenso histórico de lutas sociais de Altamira - principalmente por conflitos agrários (Entrevista 26, Movimento Xingu Vivo para Sempre, 2016) - e os diversos problemas decorrentes da implementação da usina, os procuradores que estavam iniciando sua carreira já chegavam deparando-se com inúmeros dilemas. Como relata uma das procuradoras:

"foi bem impactante, porque assim que eu cheguei estava no auge da questão de reassentamento, então estava sempre com muita gente, e todo mundo preocupado, porque as pessoas estavam sendo retiradas e não sabiam para onde iam, se iam, ou como receberiam o valor da indenização. [...] Então eu já cheguei nesse turbilhão" (Entrevista 53, MPF, 2016).

Em meio a esse "turbilhão" que funcionava como tapete de entrada da PRM-Altamira, os procuradores da cidade buscavam ajuda com seus colegas de outras sedes do MPF, que auxiliavam "amadurecendo a questão, dialogando, construindo com você a melhor decisão a tomar" (Entrevista 28, MPF, 2016). Assim, tanto em Brasília - principalmente a partir da Procuradoria Federal dos Direitos do Cidadão (PFDC), da Câmara de Meio Ambiente e Patrimônio Cultural e da Câmara de Populações Indígenas e Comunidades Tradicionais -, como na sede da procuradoria de Belém, onde trabalhavam alguns dos procuradores mais antigos do caso, havia procuradores que auxiliavam o trabalho dos servidores do MPF em Altamira (Entrevista 21, MPF, 2016).

Procuradores de Brasília ajudavam, por exemplo, na esfera judicial "fazendo recursos extraordinários para o STF [Supremo Tribunal Federal]" (Entrevista 15, MPF, 2015). Esse foi o caso da ACP de $2006^{23}$, questionando a decisão do Congresso Nacional de aprovar 
o projeto da barragem sem a realização de consultas prévias às comunidades indígenas, no qual uma da procuradoras de Brasília escreveu o recurso da ação (Entrevista 15, MPF, 2015). Já os procuradores de Belém, em especial dois deles, que estão envolvidos com o caso de Belo Monte desde o início da participação do MP, permaneceram ativos no processo fornecendo uma "memória institucional" (Entrevista 21, MPF, 2016) sobre o histórico da atuação do MPF no caso. Um desses procuradores explica:

"foi por isso [rotatividade de procuradores na PRM-Altamira] que nós dois nos mantivemos sempre tão ligados ao tema, que era para fazer essa memória. Independente de quem fosse o procurador que estava lá, a gente ajudava na transmissão até ele se empoderar daquele conhecimento e tocar sozinho, mas sempre tinha alguém com condições de falar: "oh tem uma memória aqui, isso aqui tem uma história, isso tem compromissos que já foram assumidos, isso tem notícias que já passaram pelo MP”, então a gente fazia essa transição. Tanto que são raríssimas as ações propostas pelos colegas de Altamira, seja lá quem for, que não tenham sido assinadas por colegas de Belém. E não só assinadas, gestadas, discutidas, justamente para ter essa lógica de continuidade no processo" (Entrevista 21, MPF, 2016).

Portanto, práticas de articulações internas foram fundamentais na construção de ações civis públicas, e ainda da inspeção, que contou com membros do MPF de três sedes diferentes (Altamira, Belém e Brasília). Procuradores também lançaram mão de um terceiro tipo de prática, a bricolagem, entendida como a recombinação criativa de recursos existentes em diferentes maneiras a fim de resolver problemas. Como resumem Berk e Galvan $\left(2009\right.$, p. 550, tradução nossa ${ }^{24}$ ), na bricolagem "as pessoas voltam aos conhecimentos que possuem sobre partes da organização e recombinam essas partes para montar uma nova resposta a um novo problema”. Assim, a ideia de bricolagem refere-se a uma ação de improvisação, facilitada por múltiplas redes pessoas e institucionais (Ansell, 2013; Abers; Keck, 2013).

Nesse sentido, entendo por bricolagem as práticas por meio dos quais procuradores utilizavam os recursos que tinham a disposição de maneiras que fogem ao repertório convencional da instituição. Um exemplo de bricolagem são os despachos. Cansada de lidar com a morosidade e as derrotas no Judiciário, uma das procuradoras conta que, ao invés de ajuizar ações, ela passou a tentar trabalhar cooperativamente com órgãos licenciadores - como o IBAMA e a FUNAI - que têm o poder de pressionar a Norte Energia a cumprir os requisitos do licenciamento ambiental. Esse acionamento ocorria através de um instrumento chamado de despacho, que pode ser entendido como

"uma forma de manifestação no procedimento administrativo, no inquérito civil. [...] Despacho é a forma como eu me manifesto nesses inquéritos. Então eu instruo o despacho com todos o argumentos que eu poderia propor uma ação judicial. E aí em vez de propor a ação, eu mando [o despacho] para o IBAMA" (Entrevista 67, MPF, 2016). 
A diferença do despacho em relação a outros instrumentos de ação, como as ações judiciais e a recomendação ${ }^{25}$, é que "a recomendação, se eles não cumprirem, eu tenho que tomar alguma providência. $\mathrm{O}$ despacho não. Eu estou dizendo: você está aí longe IBAMA, então o que eu estou vendo aqui é isso". Nesse sentido, os recursos que seriam mobilizados para ajuizar ações são transformados em despachos que buscam resolver problemas extrajudicialmente - evidenciando o porquê entendo ele como um exemplo de bricolagem. O despacho foi utilizado em diversas situações, como por exemplo no próprio caso dos ribeirinhos, nos quais procuradores persuadiram o IBAMA a exigir que a Norte Energia reconhecesse a dupla moradia, que era caráter constitutivo do modo de vida das populações ribeirinhas (Entrevista 67, MPF, 2016).

\section{De práticas a capacidades: como organizações aprendem e se transformam}

As práticas acionadas por procuradores no contexto de Belo Monte produziram diversos efeitos no processo de implementação da usina, como, por exemplo, a judicialização de alguns conflitos e a garantia de determinados direitos para alguns dos grupos atingidos pela barragem. Meu objetivo neste artigo, contudo, é compreender mais sistematicamente os efeitos dessas práticas dentro do próprio MPF. Afinal, diversos dos procuradores entrevistados enfatizavam como sua atuação no caso de Belo Monte estava transformando as maneiras pelas quais o MPF intervém em processos de instalação de grandes obras (Entrevista 11, MPF, 2015; Entrevista 21, MPF, 2016). Como explica uma das procuradoras, "por se tratar de um caso inédito em termos de complexidade e tamanho dos interesses envolvidos, [Belo Monte] serve como experiência para o aperfeiçoamento da atuação em casos futuros" (Entrevista 13, MPF, 2015).

É nesse sentido que proponho entender as práticas de procuradores do MPF como processos de construção e transformação de capacidades estatais. Como mostrarei nessa seção, algumas dessas práticas geram aprendizagens organizacionais que influenciam o modo como procuradores lidam com casos futuros semelhantes. Em outras palavras, entendo que podemos pensar nessas práticas - recrutamento de aliados, articulações internas e bricolagens - enquanto processos de construção e transformação de capacidades estatais à medida que elas mudam as maneiras pelas quais os agentes dessas organizações lidam com problemas futuros.

Antes de entrar na explicação sobre como as práticas de procuradores no caso de Belo Monte criavam e transformavam capacidades dentro do Ministério Público Federal,

25 As recomendações são documentos através dos quais o MPF adverte outros atores sobre possíveis erros de conduta e sobre a própria posição do MPF no assunto. Como explica um dos procuradores, "o instituto jurídico da recomendação é um instituto extrajudicial de advertência do sistema jurídico nacional. Porque nós falávamos: "oh, isso aqui não está de acordo com a norma, se você fizer, você deve adequar à norma". Se ele não adequasse, tinha que entrar com a ação" (Entrevista 77, MPF, 2017). 
considero importante fazer duas observações. Em primeiro lugar, cumpre ressaltar que os processos de construção e transformação de capacidades não são automáticos. $\mathrm{O}$ modelo proposto neste trabalho não é probabilístico causal - no sentido que a presença de determinadas variáveis tende a produzir determinados resultados -, mas possibilístico (Hirschmann, 1970). Em outras palavras, as práticas dos atores não geram necessariamente aprendizagem organizacional e tampouco a construção de capacidades, podendo levar a frustração, fracassos, ou conflitos (Ver também Abers; Keck, 2013). Em alguns momentos, contudo, elas produzem efeitos transformadores nas rotinas e entendimentos organizacionais. De que maneiras e sob quais mecanismos atores constroem capacidades nas organizações em que trabalham tornam-se, portanto, perguntas empíricas contextualmente situadas.

Em segundo lugar, apesar de estar preocupado em como práticas se transformam em capacidades, vale notar que, para que essas práticas se materializem, elas se apoiam em diversos tipos de capacidades já existentes. Por exemplo, para que procuradores ajuízem uma ação civil pública, eles dependem de capacidades administrativas do MPF para mobilizar recursos e executar suas investigações. Entendo que isso não implica necessariamente em um argumento tautológico - de que capacidades possibilitam a materialização de práticas que podem construir capacidades -, mas no reconhecimento de que capacidades estatais são dinâmicas: elas estão em permanente (re)produção e transformação no cotidiano da administração pública. Neste artigo, meu foco está nos processos através dos quais práticas se transformam em capacidades, e não em como capacidades permitem que atores acionem determinadas práticas.

$\mathrm{Na}$ atuação de procuradores no caso de Belo Monte, o acionamento de práticas de recrutamento de aliados, por exemplo, contribuiu para a construção de capacidades participativas, que podem ser entendidas como "as habilidades das burocracias de criarem mecanismos de articulação para fora do Estado" (Pereira, 2014, p. 54; Grindle, 1996, p. 10; Souza, 2014, p. 53). Apesar do MPF já possuir uma inserção com grupos sociais diversos mesmo antes de Belo Monte (Entrevista 76, ISA, 2016), foi a mobilização intensa de procuradores acerca da hidrelétrica que aproximou o órgão de OMSs e da população local (Entrevista 24, Movimento XinguVivo para Sempre, 2016). Os próprios procuradores foram percebendo a importância dos contatos com grupos sociais diversos, recomendando que seus colegas interagissem, por exemplo, com comunidades impactadas pela barragem:

"Como eu fazia, por exemplo, com os procuradores que chegavam do sul, com uma realidade completamente diferente? Sabe qual era a tática? "Vai para a aldeia. Fica na aldeia". [...] E quando voltava, voltava completamente mudado. Não tem pedagogia melhor do que essa de conhecer a realidade. $\mathrm{O}$ choque de realidade que levava era o suficiente para o cara vir e preparar a ação contra Belo Monte. [...] E ainda voltava revoltado com o que governo fazia”" (Entrevista 79, MPF, 2017).

Nesse sentido, consolidou-se um posicionamento - que atravessava todos os dez procuradores entrevistados - de que o MPF precisava de aliados, isto é, de que o órgão precisava construir capacidades participativas que os possibilitasse atuar em determinadas 
temáticas. Como explica um dos procuradores, "no MP, para a gente foi um aprendizado nesse sentido, que a gente precisa de um canal de comunicação efetivo, mais direto. [...] Você precisa de um MP que tenha a sociedade civil do seu lado, e da sociedade civil toda, que a gente tenha muita informação" (Entrevista 79, MPF, 2017).

Já as práticas de articulações internas, por outro lado, contribuíram para a consolidação de um entendimento sobre a importância dos diálogos internos entre diferentes sedes do MPF, o que procuradores também interpretam como um aprendizado. A mobilização de procuradores de Belém e de Brasília para ajudar seus colegas em Altamira no caso de Belo Monte, nesse sentido, despertou a atenção do MPF para os potenciais de ações coordenadas entre diferentes instâncias do órgão:

"E ainda existe, e não só dos procuradores, é do MP inteiro. Existe dentro do MP uma sensibilidade muito grande com relação a Belo Monte, a ponto de você ter um grupo, um centro de apoio, então você nunca está sozinho" (Entrevista 15, MPF, 2015).

Portanto, podemos entender que a atuação do MPF no caso de Belo Monte - e mais especificamente as articulações internas entre procuradores - contribuíram para a construção e consolidação de uma dinâmica de diálogos dentro da própria organização, envolvendo diferentes instâncias e sedes. Essas capacidades poderiam ser entendidas como dimensões do que é geralmente chamado de capacidades técnico-administrativas (Pires; Gomide, 2014). A especificidade desses processos comunicativos dentro do MPF, contudo, me leva a entendê-las como capacidades de coordenação intraburocráticas - nas quais atores de uma mesma agência estatal trabalham em conjunto em torno de torno de pautas em comum.

Além disso, ao lançarem mão de práticas de bricolagens - como os despachos - procuradores construíram também capacidades de coordenação interburocrática, nas quais diferentes agências estatais colaboram para implementar determinadas pautas (Pereira, 2014). Transformando evidências de ações judiciais em despachos voltados à negociação com órgãos licenciadores, como o IBAMA e a FUNAI, procuradores (re)construíam as maneiras pelas quais o MPF interagia com essas organizações. De acordo com uma das procuradoras: "Isso para mim é um aprendizado, que a gente atue junto com o licenciador, até onde é possível" (Entrevista 14, MPF, 2015). Ao acionarem órgãos licenciadores como o IBAMA e a FUNAI, tentando persuadi-los da legitimidade de suas demandas para que pressionassem a empresa Norte Energia a cumpri-las, procuradores construíam um entendimento de que esgotar as vias extrajudiciais - e, portanto, as negociações com outras agências estatais, uma característica central das capacidades interburocráticas - poderiam gerar resultados mais efetivos do que a judicialização. Como explica um deles, "o MPF vem aprendendo muito na atuação com Belo Monte. E uma das questões é sempre tentar esgotar o máximo todas as vias extrajudiciais para que o problema seja resolvido sem judicializar a questão, que envolve muitas incertezas" (Entrevista 28, MPF, 2016). 
Um dos exemplos mais evidentes refere-se à relação do MPF com o IBAMA, agência responsável pela condução do processo de licenciamento do empreendimento. Se durante um primeiro momento o órgão tinha uma relação com o IBAMA baseada apenas na demanda formal de informações e em ações judiciais - nas quais o IBAMA muitas vezes era o próprio réu -, com o passar do tempo os procuradores, ao acionarem despachos, reconfiguravam sua dinâmica de interação com os servidores do IBAMA. Como explica um dos procuradores, "a nossa relação com o IBAMA praticamente não existiu.Você não conseguia ter diálogo, até para coisas pequenas. [...] Essa coisa de você bater no IBAMA e conversar com o IBAMA também é fruto de Belo Monte. Isso tudo é resultado direto de Belo Monte, de amadurecimentos institucionais".

Os impactos que essas práticas produzem no MP (enquanto uma organização estatal) ficam ainda mais claros quando procuradores revelam como sua atuação no caso de Belo Monte tem sido uma plataforma para a intervenção do órgão em casos semelhantes - como por exemplo na hidrelétrica de São Luís do Tapajós e de Teles Pires. Afinal, como afirma um dos procuradores, "acho que [a atuação em Belo Monte] primeiro criou um padrão de atuação, um histórico de atuação que vem sendo replicado em muitos outros casos" (Entrevista 11, MPF, 2015).

Na realidade, o próprio entendimento do que era "papel" do MPF no contexto de instalação de grandes projetos se transformou a partir da atuação de procuradores no caso de Belo Monte. De acordo com um dos procuradores, antes de Belo Monte o foco do MPF estava inteiramente concentrado no momento da Licença Prévia - e assim na possibilidade ou não de barrar o empreendimento:

"Vários empreendimentos em que você tem toda uma discussão judicial na
judicialização do licenciamento, e ela vai estar só na Licença Prévia. Você
vai discutir se o estudo de licenciamento ambiental foi bem feito, se não foi
bem feito. Concedida a LP, era como se ficasse: "ok, perdemos, esquece". E
aquilo ninguém acompanhava, não havia um histórico. Belo Monte a gente
tem acompanhamento e muita briga na LP, tem discussão na LI, [...] até na
LO.A gente vem acompanhando tudo, brigando" (Entrevista 21, MPF, 2016).

Vemos, portanto, como as maneiras pelas quais organizações estatais atuam na implementação de políticas públicas não podem ser tomadas como algo "dado". Agentes estatais, em diversos momentos, aprendem com suas práticas, construindo e transformando as capacidades que suas organizações têm para agir.

\section{Considerações Finais}

Neste artigo, busquei contribuir para o debate sobre capacidades estatais a partir de um estudo etnográfico sobre a atuação do Ministério Público Federal no contexto da implementação da usina de Belo Monte. A usina, que hoje já está em operação no rio Xingu, foi (e ainda vem sendo) amplamente questionada por diversos atores, como organizações 
de movimentos sociais, populações locais e agências estatais, como o próprio MPF. A participação do Ministério Público Federal nesse caso já ultrapassa dezesseis anos (2001-), durante os quais o órgão interviu de maneiras diversas, como por exemplo através de ações judiciais e instrumentos extrajudiciais (como despachos e inspeções) que buscavam pressionar o empreendedor da usina - a empresa Norte Energia - a cumprir com demandas relacionadas à mitigação de impactos sociais e ambientais provocados pela barragem.

Ao olhar para esse processo etnograficamente, busquei abrir a "caixa preta" do $\mathrm{Mi}$ nistério Público e entender quem são os sujeitos que dão vida a essa instituição, investigando como trabalhavam procuradores da República durante o caso de BM. Nessa linha, iluminei três tipos de práticas acionadas por procuradores: os recrutamento de aliados, as articulações internas e as bricolagens. Mostrei ainda como essas práticas não produziram efeitos apenas na política pública, mas também no MP enquanto uma organização. O argumento deste artigo é que as práticas acionadas por procuradores no caso de Belo Monte - ou pelo menos parte delas - geraram aprendizagens organizacionais que se traduziram na construção e na transformação de capacidades dentro do próprio Ministério Público, que passou a rever a reavaliar o modo como atua na instalação de grandes projetos.

Nesse sentido, entendo que este estudo contribui para os debates em torno de capacidades estatais ao enfatizar e mostrar o caráter dinâmico dessas capacidades, que ao invés de serem tomadas como algo "dado", passam a ter suas origens e mudanças exploradas analiticamente. Os processos e mecanismos por meio dos quais capacidades estatais são construídas, (re)produzidas e transformadas em organizações do Estado se tornam, portanto, perguntas empíricas contextualmente situadas.

Por fim, ao mostrar como as capacidades de uma organização estatal - o MPF - são criadas e transformadas, este estudo reforça compreensões de que o Estado e suas organizações são melhor compreendidos não como algo fixo, mas como processos e redes em movimento. Afinal, o Estado "não é um ente dotado de consciência e intenção, tampouco é uno nem uma "coisa" palpável, senão feixes de relações de poder" (Castilho; Souza Lima; Teixeira, 2014, p. 13). Nesse sentido, ressalto neste trabalho os potenciais de contribuição de análises micro - que analisam os atores que dão vida aos processos e braços estatais - para os estudos de capacidades estatais. Entendo que nosso desafio enquanto pesquisadores torna-se, assim, traçar as conexões que ligam o Estado no nível "micro" para (re)produções e transformações no nível "macro", ou seja, entender como as práticas de burocratas nos ajudam a compreender os processos por meio dos quais capacidades de organizações estatais são criadas e transformadas ao longo do tempo.

\section{Referências}

ABERS, Rebecca; KECK, Margaret. Practical Authority. Agency and Institutional Change in Brazilian Water Politics. New York: Oxford. 2013.

ABRUCIO, Fernando. Três agendas, seus resultados e um desafio: balanço recente da administração pública federal brasileira. Desigualdade \& Diversidade - Dossiê Especial, 2011, pp. 119-142. 
; LOUREIRO, Maria Rita. Finanças Públicas, Democracia e Accountability: Debate Teórico e o Caso Brasileiro. In: ENCONTRO ANUAL DA ANPOCS, XXIX, 2005, Caxambu, Minas Gerais. Anais... São Paulo: Associação Nacional de Pós-Graduação e Pesquisa em Ciências Sociais, 2005.

ANSELL, Chris. Ecological Explanation. In: BERK, Gerald et al. Political Creativity. Reconfiguring Institutional Order and Change. Pennsylvania: University of Pennsylvania Press, 2013.

ARANTES, Rogério Bastos. Direito e Política: O Ministério Público e a Defesa dos Direitos Coletivos. Revista Brasileira de Ciências Sociais, v. 14, n. 39, 1999.

- Ministério Público e Política no Brasil. São Paulo: Sumaré. 2002.

Ministério Público na fronteira entre a Justiça e a Política. Justitia, v. 197, p. 325-335, 2007.

BERK, Gerald; GALVAN, Dennis. How people experience and change institutions: a field guide to creative syncretism. Theory and Society, v. 38, p. 435-580, 2009.

. Processes of Creative Syncretism. Experiential Origins of Institutional Order and Change. In: BERK, Gerald; GALVAN, Dennis; HATTAM,Victoria. Political Creativity. Reconfiguring Institutional Order and Change. Pennsylvania: University of Pennsylvania Press, 2013. p. 29-54.

BESLEY, Timothy; PERSSON, Torsten. State Capacity, Conflict, and Development. Econometrica, v. 78, n. 1, p. 1-34. 2010.

BERMANN, Célio. O projeto da Usina Hidrelétrica Belo Monte: a autocracia energética como paradigma. Novos Cadernos NAEA, v. 15, n. 1, pp. 5-23. 2012.

CÁRDENAS, Mauricio. State Capacity in Latin America. In: LATIN AMERICAN AND CARIBBEAN ECONOMIC ASSOCIATION, 2009, Buenos Aires, Argentina, Anais... Bogotá, Colômbia: Latin American and Caribbean Economic Association, 2009.

CARVALHO, Georgia. Environmental Resistance and the Politics of Energy Development in the Brazilian Amazon. The Journal of Environment \& Development, v. 15, n. 3, p. 245-268, 2006.

CASTILHO, Sérgio; SOUZA LIMA, Antônio Carlos; TEIXEIRA, Carla C. (Org.). Antropologia das Práticas de Poder: reflexões etnográficas entre burocratas, elites e corporações. Rio de Janeiro: Contra Capa, 2014.

CINGOLANI, Luciana. The State of State Capacity: a review of concepts, evidence and measures. UNUMERIT Working Paper Series, Maastricht University, 2013-053, p.1-52. Disponível em: < http://digitalarchive. maastrichtuniversity.nl/fedora/get/guid:25cb727f-2280-41f0-a1da-ecf3ac48230f/ASSET1>. Acesso em: 31 out. 2017.

COSLOVSKY, Salo. Compliance and Competitiveness: How Prosecutors Enforce Labor and Environmental Laws and Promote Economic Development in Brazil. 2009. 187 f. Tese (Doutorado) - Massachussets Institute of Technology. 2009.

DEWEY, John. Democracy and Education. The Middle Works, 1899-1924,Volume 9: 1916. Editado por Jo Ann Boydston . Carbondale and Edwardsville: Southern Illinois University Press, 1980.

EVANS, Peter; RUESCHEMEYER, Dietrich; SKOCPOL, Theda. Bringing the State Back In. Cambridge: Cambridge University Press, 1985.

GARVIN, David. Building a Learning Organization. Harvard Business Review, 1993, pp. 78-90.

GRINDLE, Merilee Serrill. Challenging the State: crisis and innovation in Latin America and Africa. Cambridge: Cambridge University Press, 1996.

HALLETT, Tim;VENTRESCA, Marc J. Inhabited institutions: social interactions and organizational forms in Gouldner's Patterns of Industrial Bureaucracy. Theory and Society. v. 35, p. 213-236, 2006.

HERZFELD, Michael.The social production of indifference: exploring the symbolic roots of Western bureaucracy. Chicago: The University of Chicago Press, 1993. 
HIRSCHMANN,Albert. Exit, Voice and Loyalty: responses to decline in firms, organizations and states. Cambridge: Harvard University Press, 1970.

HOCHSTETLER, Kathryn; KECK, Margaret E. Greening Brazil. London: Duke University Press, 2007.

The politics of environmental licensing: energy projects of the past and future in Brazil. Studies in Comparative International Development, v. 46, n. 4, p. 349-371, 2011.

KERCHE, Fábio. Autonomia e Discricionariedade do Ministério Público no Brasil. DADOS, v. 50, n. 2, p. 259$279,2007$.

LEMGRUBer, Julita et al. Ministério Público: Guardião da Democracia Brasileira?. Rio de Janeiro: Centro de Estudos de Segurança e Cidadania (Cesec). 2016.

LEVITT, Barbara; MARCH, James. Organizational Learning. Annual Review of Sociology. v. 14, p. 319-340, 1988.

LOSEKANN, Cristiana. Mobilização do Direito como Repertório de Ação Coletiva e Crítica Institucional no Campo Ambiental Brasileiro. DADOS, v. 56, n. 2, p. 311-349, 2013.

LUNA, Juan Pablo; MAUREIRA, Sergio. State Capacity and Democratic Governance in Latin America:A Survey Data-Based Approach to Measurement and Assessment. Americas Barometer Insights, n. 102, 2014. Disponível em: <http://www.vanderbilt.edu/lapop/insights/IO902en.pdf>. Acesso em: 27 nov. 2017.

MARCH, James. Exploration and Exploitation in Organizational Learning. Organization Science. v. 2, n. 1, pp. 71-87, 1991.

MAZZUCA, Sebastián L. Legitimidad, autonomía y capacidad: conceptualizando (una vez más) los poderes del Estado. Revista de Ciencia Política, Santiago, v. 32, n. 3, p. 545-560, 2012.

MCALLISTER, Lesley K. Making Law Matter: Environmental Protection \& Legal Institutions in Brazil. Stanford: Stanford University Press, 2008.

MPF. Ministério Público Federal. Relatório de Inspeção Interinstitucional: áreas ribeirinhas atingidas pelo processo de remoção compulsória da UHE Belo Monte. Altamira, Pará: Ministério Público Federal, 2015.

MIGDAL, Joel S. State in Society. Studying How States and Societies Transform and Constitute One Another. Cambridge: Cambridge University Press, 2004.

NONAKA, Ikujiro; TOYAMA, Ryoko; BYOSIÈRE, Philippe. A theory of organizational knowledge creation: understanding the dynamic process of creating knowledge. In: DIERKES, Meinolf et al. (Ed.). Handbook of organizational learning and knowledge. Oxford: Oxford University Press, 2001. p. 487-491.

OLIVEIRA, João Pacheco. Pluralizando Tradições Etnográficas: sobre um certo mal-estar na Antropologia. Cadernos do LEME, Campina Grande, v. 1, n. 1, p. 2-27, 2009.

ORTENBLAD, Anders. On differences between organizational learning and learning organization. The Learning Organization. v. 8, n. 3, p. 125-133, 2001.

OTTERVIK, Mattias. Conceptualizing and Measuring State Capacity:Testing the Validity of Tax Compliance as Measure of State Capacity. The Quality of Government Institute working paper, p. 20, 2013.

PAINTER, Martin; PIERRE, Jon (Org.). Challenges to State Policy Capacity. Global Trends and Comparative Perspectives. New York: Palmgrave Macmillan. 2005.

PEIRANO, Mariza. Etnografia não é Método. Horizontes Antropológicos, Porto Alegre, ano 20, n. 42, p. 377-391, 2014.

PEREIRA, Ana. A construção de capacidade estatal por redes transversais: o caso de Belo Monte. 2014. 265 f. Tese (Doutorado em Ciência Política) - Instituto de Ciências Políticas, Universidade de Brasília. 2014.

PERIN, Marcelo et al. Processo de Aprendizagem Organizacional e Desempenho Empresarial: O Caso da Indústria Eletroeletrônica no Brasil. RAE-eletrônica, v. 5, n. 2, 2006.

PIRES, Roberto; GOMIDE, Alexandre. Burocracia, Democracia e Políticas Públicas: arranjos institucionais de políticas de desenvolvimento. IPEA: Brasília, 2014. (Texto para Discussão 1940). 
RICE, Susan; PATRICK, Stewart. Index of State Weakness In The Developing World. Washington: The Brookings Institution, 2008.

SADEK, Maria Tereza (Org.). O Ministério Público e a Justiça no Brasil. Rio de Janeiro: Centro Edelstein de Pesquisas Sociais, 2010. Disponível em: < https://static.scielo.org/scielobooks/qb3pp/pdf/castilho-9788579820373.pdf > . Acesso em: 01 nov. 2017.

SÁNCHEZ, Luis Enrique. Avaliação de impacto ambiental: conceitos e métodos. 2. ed. [s.1.] Oficina de textos, 2013. SCHLUCHTER, Wolfgang. The Rise of Western Rationalism. Max Weber's

Developmental Theory (1979). Los Angeles: University of California Press, 1985.

SCHULZ, Martin. The uncertain relevance of newness: Organizational learning and knowledge flows. Academy of Management Journal, v. 44, n. 4, p. 661-681, 2001.

SENGE, Peter. The fifth discipline: the art and practice of the learning organization (1990). New York: Currency Doubleday, 2004.

SOUZA, Clóvis. Capacidades Estatais para a Promoção de Processos Participativos: uma análise da forma de organização de Conferências Nacionais. 2014. 201 f. Tese (Doutorado em Ciência Política) - Instituto de Ciências Políticas, Universidade de Brasília.

STATA, Roy. Organizational Learning - The Key to Management Innovation. MIT Sloan Management Review, v. 30, n. 3, 1989.

STEINMETZ, George. State/culture: state formation after the cultural turn. Cornell: Cornell University Press, 1999.

VILAÇA, Luiz. Costuras, deslocamentos e bricolagens: a atuação de procuradores do Ministério Público Federal no caso de Belo Monte. 2017. 151 f. Dissertação (Mestrado em Ciência Política) - Instituto de Ciências Políticas, Universidade de Brasília, 2007.

WEBER, Max. Economia e Sociedade. Brasília: Editora UnB, 2004. (Volume 2). 


\title{
From practices to state capacities: the role of public prosecutors on the Belo Monte case
}

\begin{abstract}
This research is based on an ethnographic analysis of the construction and transformation of state capacities within the Public Prosecutor's Office (Ministério Público Federal - MPF) throughout the implementation of the Belo Monte dam. Since 2001, prosecutors have been promoting several actions - judicial and off the courts - that challenge the dam's implementation model and try to reduce its social and environmental impacts. In this article, I investigate how three types of prosecutors' practices - allies recruiting, internal collective articulations and bricolages - changed the way the organization deals with the implementation of large projects. I argue that these practices have produced an organizational learning which resulted in the construction and transformation of different types of capacities within the MPF, thus highlighting the dynamicity of state capacities and the importance of investigating what state agents are actually doing when they put these capacities in motion.
\end{abstract}

Key words: Public Prosecutor's Office, Belo Monte, state capacities, practices.

\section{De prácticas a pericias: la actuación de los Fiscales del Ministerio Público Federal en el caso de Belo Monte}

\section{Resumen}

Esa pesquisa analiza etnográficamente los procesos de construcción de capacidades estatales en el Ministerio Público Federal (Ministério Público Federal - MPF) en el contexto de la implementación de la usina hidroeléctrica Belo Monte. Desde el año 2001, Fiscales han promovido una variedad de acciones - judiciales y extrajudiciales -, con el fin de cuestionar el modelo de implementación de la usina y mitigar sus impactos socioambientales. En ese artículo, investigo como tres tipos de prácticas de los Fiscales - los reclutamientos de aliados, las articulaciones internas y los bricolajes - cambiaron las formas de actuación de la organización en procesos de implementación de grandes proyectos. Argumento que esas prácticas generaran aprendizajes organizacionales que se tradujeron en la construcción y transformación de diferentes tipos de capacidades dentro del MPF, lo que resalta el carácter dinámico de las capacidades estatales y la relevancia de investigar lo que están haciendo los actores estatales que materializan esas capacidades.

Palabras clave: Ministerio Público, Belo Monte, capacidades estatales, prácticas. 
